\title{
Optimization of Lubricant Consumption in the Wheel/Rail Friction System
}

\author{
Vyacheslav T. Volov ${ }^{1}$, Aleksey A. Bondarenko ${ }^{1}$, Dmitriy V. \\ Ovchinnikov $^{1}$, Vitaliy V. Atapin ${ }^{1}$, Lei Kou ${ }^{2}$
}

${ }^{1}$ Samara State Transport University

First Bezimyannii per.18, 443066 Samara, Russia

volovvt@samgups.ru, bondarenko@infotrans-logistic.ru,

ovchinnikov@samgups.ru, atapin@infotrans-logistic.ru

${ }^{2}$ Institute of Railway Systems and Public Transport, TU-Dresden

Hettnerstr. 1, 01069 Dresden, Germany

lei.kou@tu-dresden.de

\begin{abstract}
The work examines the results of the study aimed at minimizing the consumption of lubricants in the wheel/rail interface. A numerical simulation of a circular slip path was carried out based on the theory of experiment planning. The simulation was performed depending on the wheel radius, the difference between the radii of the wheels contacting the flange and rim with the railhead, the taper angle of the flange and the angle of attack. According to Box-Wilkson steepest ascent method, geometrical parameters of the wheel/rail interface were obtained, making it possible to reduce the circular slip path by $30 \%$. These results can significantly decrease the number of relevant field studies and lubricant consumption in the wheel-rail system. Mathematical modeling enabled the analysis of the stress-strain state of the "wheel-rail" system, at lateral contact, with the addition of friction forces to the contact zone. The simulation results show the importance of using rail lateral lubrication as one of the means to extend the service life of this expensive track structure, in small radius curves.
\end{abstract}

Keywords: slip path; angle of attack; flange angle; regression equation; Box-Wilkson method; track infrastructure; rail lubrication; stationary rail lubricators; mobile rail lubricators; stress calculation; lateral contact; moment of forces 


\section{Introduction}

A rail lubrication is an important maintenance technique that decreases rail-wheel friction and therefore can cause the significant reduction of rail wear and rail contact $(\mathrm{RCF})$ defects in railway curves. This results in extending the life cycle of rails, improvement the wheel-rail contact and decreasing the overall life cycle costs. The research of rail lubrication is presented by many studies of the last years. The experimental investigation [1] was carried out to study and compare the response to cyclic loading of the high-performance railway wheel steels ER8 EN13262. Rolling contact tests were performed with the same contact pressure, rolling speed and sliding ratio, varying the lubrication regime to simulate different climate. The distribution of crack length and depth at the end of the dry tests was analyzed to quantify the damage. A comprehensive review of recent research in wheel-rail contact tribology and lubrication is presented in [2]. An experimental investigation of the lubricant Optimization is presented in [3] using a test rig from a scaled wheel and a short section of rail, and a modern trackside lubricator set-up. The results showed that increasing pickup of grease can be expected when an additional component was fitted to a regular grease delivery unit on the rail. The effect of temperature on bulb size of grease was also investigated. The paper [4] provides a study of the effectiveness of the technology of lubrication of the rail roll surface in the curve by the locomotive in the train. The reduction of the lateral impact on the track by reducing the constant of friction on the roll surface of the internal rail and the side surface of the outer railhead is indicated. The research [5] presents designing of disc-on-disc wear testing instrument with wheel material and rail one specimen. Dry lubricant used was graphite bar polished onto wheel specimen surface. The result of research showed that graphite could adhere to wheel surface and penetrate into the cracks of contact between wheel and railway. In the study [6], the influence of three commercially applied railway greases on the wear and friction behavior, as well as, the load-carrying ability, were investigated. The test results explained that the rail curve greases are very soft in texture yet have the stable structure over a high-temperature range. The pin-ondisc test model system was used in [7] to simulate contact-wear between wheel flange and rail gauge corner in dry and lubricated tests. The results show that for the lubricated tests, mass loss was significantly lower and regardless of both, hardness ratio and normal load, than in the other tests. The study [8] evaluates the effect of roughness and temperature on the friction coefficient of wheel and rail materials by applying different amounts of railway lubricant grease using a pinon-disc tribometer and simulating a wheel-flange and rail-gauge contact pressure. The results show that for a well-lubricated contact, the rougher surfaces yield a lower friction coefficient for the same contact pressure and sliding velocity.

The wheel-rail interaction is a key issue of railway vehicle dynamics that influence rail wear and RCF defects. Many scholars have done in-depth research on this issue [9-17]. Especially when the train passes through the high-speed 
curve, the influence of the line change on the interaction on the wheel-rail is more severe, the impact force of the wheel-rail is greater, and the damage to the wheelrail system structure will be further aggravated, which will affect the safety, stability and stability of the train operation. The modeling, analysis and evaluation methods of vehicle curve passing performance are the key points of wheel-rail relationship research [18-21]. Rapid wear and tear not only consumes a lot of maintenance labor force, but also requires frequent damage detection [22], which will make a lot of investment. There are some outstanding research results. Yang G. et al used the modified Elkins wear index method and the ANSYS and SIMPACK co-simulation method to study the influence of the wheel-rail contact geometric parameters under a high-speed train on wheel-rail wear [23]. The Lagrangian Euler finite element wheel-rail rolling contact model was established by Chang C. and Wang C. to study the various aspects of the wheelrail contact system. It provides a stable and predictable rolling contact model for different materials and geometric configurations. At the same time, it analyzes the distribution of contact stress, contact mode and relative sliding velocity. The rotation and distribution of friction in the contact mode have a huge impact on the wheel-rail system in terms of vibration, adhesion and wear [24]. The paper [25] presents an innovative solution for monitoring the status of temperature and other atmospheric conditions. The solution is an effective support for the application of digital twins to railway turnouts and ongoing surveying and diagnostic work of other elements of rail transport infrastructure. N. Costa J. et al. proposed a new method was proposed to model the track so that it can be properly aligned with the body [26]. Milošević $M$ et al use the finite element model to calculate the residual stress inside the track in the wheel-rail contact [27].

At present, there are few related results to study the curve passing performance through the establishment of dynamic models. Numerous studies have shown that the wheel-rail creep rate has an important impact on wheel-rail wear. The sharp change in stress state from tension to compression is the most unfavorable condition for wheel-rail operation and lubricants can improve this unfavorable condition. Taking into account the current share of railway curves in Russia, this paper uses experimental planning theory tools to numerically optimize the geometric parameters of the circular slip path. Using the Box-Wilkson steepest ascent method, the parameters of the wheel-rail geometric interface and the 3D finite element model are obtained. The use of lubricants is quantitatively evaluated. This verifies the possibility of track lateral lubrication as a means to extend the service life of this expensive track structure on a small radius curve. 


\section{The Wear of Rails and Wheelsets in Curves}

Changes in the traffic mode, the state of the rolling stock and rail track have a significant impact on the nature of their interaction. They form one of the main factors that cause rail track irregularities in curves, wheelsets and rail wear. Over $80 \%$ of rail damage leading to their failure proved [28-30] to be on curves. This is primarily rail wear out caused by the impact of rolling stock wheels. New rolling stock wheels have the tread conicity of $1 / 20$, which enables to pass curves with a radius of $1100 \mathrm{~m}$ and over, eliminating slip rolling. Such a slip is inevitable if the curve radius is less than $1100 \mathrm{~m}$, wheels have other values of conicity, or design features of the wheelsets in a car bogie. There is a longitudinal slip of the inner wheels (blocking) or sliding of the outer wheels on the rails, thus resulting in intense wear of the rails. Large-scale inspection of wheelsets revealed only up to $10 \%$ have a conicity of $1 / 20$, others have a higher conicity (or even have negative values). The share of track curves with an average radius of $350-1100 \mathrm{~m}$ on the network of the Russian Federation amounts to about $40 \%$. For example, the length of such sections is about $56 \%$ at one of the enterprises of the track facilities of the Kuibyshev railway. (Fig. 1)

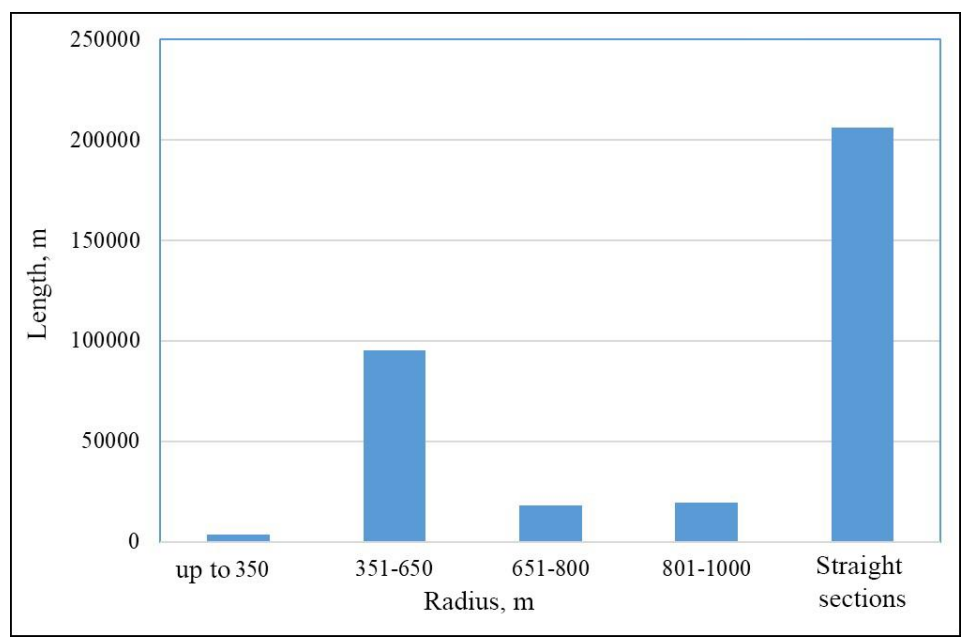

Figure 1

The share of curves at one of the enterprises of railway track facilities

The main measures to reduce the wear of rails and wheelsets in curves include the use of various lubricants, which are applied to the working surface of the railhead by different facilities and in different ways [31] [32]. In Russia at present, the number of modern rail lubricating cars is about 95 units. In addition, there are 89 mobile rail lubricators built based on reequipped locomotives. 
The network operates 8.893 stationary rail lubricators (SRL), of which 8.514 (95.7\%) are of modern type SRL. Stationary lubricators with one (SRL-02, Fig. 2) and two (SRL-02-04) nozzles and lubricators with feeder plates (SRL-02-06) are used. The lubricant is supplied with compressed nitrogen or air.

These modifications (with two nozzles) can be used both in curves exceeding 300 $\mathrm{m}$ in length and at turnouts. Single-nozzle modification is used on conventional turnouts, whereas double nozzle one is applied to symmetrical switches. Lubricators SRL02 and SRL-02-04 provide lubricant supply to the working surface of the rail through nozzles that are installed inside the track. They do not have direct contact with the rail and wheel.

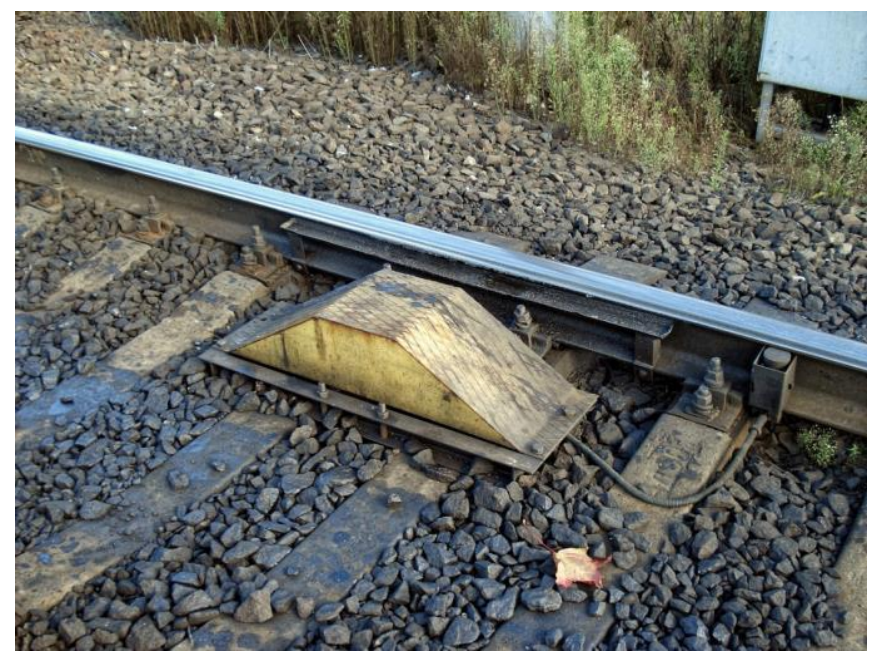

Figure 2

Stationary rail lubricator (SRL-02)

In this regard, one of the major objectives in the wheel/rail interface operation is to conclude the optimal values of lubricant consumption parameters. These parameters ensure reduced dynamic forces impact, thus achieving a decrease in the wear of the rails and bogies of the railway vehicle. At the same time, the following problems are not fully solved: optimizing lubricant consumption and the effect of lubricant on the malfunctioning in the wheel/rail interface. It is especially important for ensuring safe movement of trains on sections of high-speed and heavy-weight traffic due to increased axial loads. The primary aim of this study is to determine the optimal values of lubricant consumption parameters. 


\section{Lubricant Consumption Parameters}

According to the classical ideas of the modern theory of friction and wear, an equilibrium roughness of the contacting surfaces are formed in the process of wheel flanges slipping along the side of the railhead [33-35]. If there are not any micro irregularities, they are formed and gradually expand to the size of the equilibrium roughness. If there are initial micro-irregularities, they are smoothed by the micro-cutting of the metal (the tops of the protrusions) and it develops an equilibrium roughness.

The size of the micro-irregularities corresponding to the equilibrium roughness depends on many factors: specific pressure in the contact patch, metal hardness, lubrication, low temperature effect, slipping speed, etc. However, the most important of them is the slip. The studies [28-30] [33-35] showed that such types of slip as pseudo-slip, called "creep", slip caused by the common spinning of contacting surfaces, called "spin", and cross-slip have little impact on the lateral wear of rails and wheel flanges. This process is mainly caused by the inevitable circular slip of the pressed wheel flange along the side of the railhead during their two-point contacting, as well as the longitudinal slip of the wheel along the rail due to different lengths of the outer and inner rails in a curve and different lengths of wheel circles on these rails. Longitudinal slip along the outer rail occurs only in case of an excessive height of the outer rail.

This study proposes a solution to the problem of defining optimal values of the parameters of the wheel/rail interface corresponding to the minimum circular slip distance, which in turn leads to a lower consumption of expensive lubricants. The instruments of the experiment planning theory were used for determining the optimal geometric parameters of the wheel/rail interface [36].

Numerical optimization of the geometric parameters of the "wheel-rail" system according to the formula (1) using experiment planning and the Box-Wilkson gradient method allows to significantly narrow the search area for optimal geometric parameters in real conditions of a field experiment.

The final formula for determining the circular slip path along the length L, depending on the angle of attack $\alpha$ and the taper angle of flange $\varphi$ for new rails, has the following form (the design scheme is shown in Figure 3):

$$
\Delta l_{\rho}=\frac{L(r+\Delta r) \sqrt{1+\frac{\tan ^{2} \phi \tan ^{2} \alpha}{1-\tan ^{2} \phi \tan ^{2} \alpha}}}{r}-L
$$

Where:

L - $\quad$ The distance at which the wheel makes n revolutions 
$\Delta \mathrm{r}$ - $\quad$ The difference between the radii of the circles of contact with the flange and rim of the wheel with the rail head and the radius of the wheel in the section of the rolling circle

r - Wheel radius

$\alpha-\quad$ Angle of attack

$\varphi$ - $\quad$ Taper angle of the flange

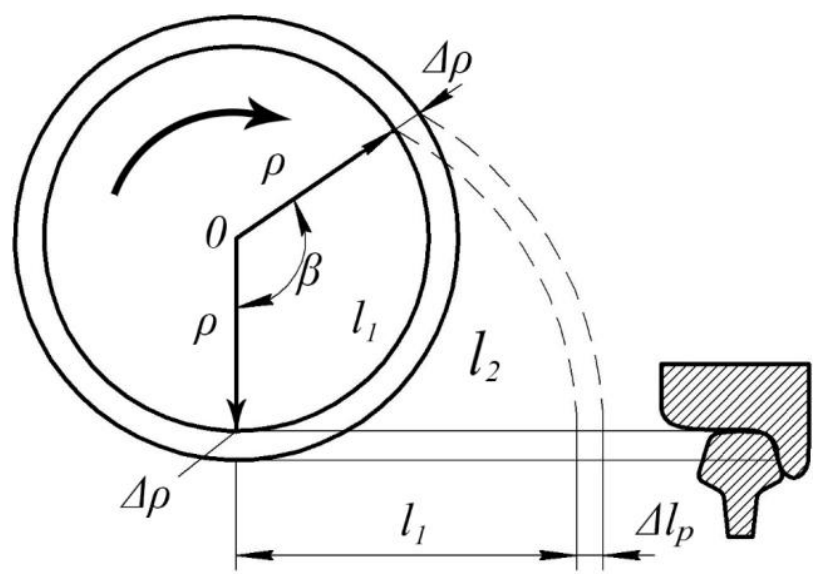

Figure 3

Diagram of the formation of a circular slip of the flange along the side of the railhead

The following factors were selected as the main ones: wheel radius $\left(\mathrm{x}_{1}\right)$, the difference between the flange tangent radius and side of the rim with the top of the railhead $\left(\mathrm{x}_{2}\right)$, flange angle $\left(\mathrm{x}_{3}\right)$, angle of attack $\left(\mathrm{x}_{4}\right)$. For the experiment, the following levels of factors were chosen:

1) For factor $(\rho): 0.9 \mathrm{~m}$ is the lower level; $0.95 \mathrm{~m}$ is the main level; $1.0 \mathrm{~m}$ is the top level of the factor

2) For factor $(\Delta \rho): 0.01 \mathrm{~m}$ is the lower level; $0.015 \mathrm{~m}$ is the main level; 0.02 $\mathrm{m}$ is the top level of the factor

3) For factor $(\varphi)$ : $60 \mathrm{deg}$ is the lower level; $70 \mathrm{deg}$ is the main level; $80 \mathrm{deg}$ is the top level of the factor

4) For factor $(\alpha)$ : $30 \mathrm{~min}$ is the lower leve; $40 \mathrm{~min}$ is the main level of the factor; $50 \mathrm{~min}$ is the top level of the factor

The encoding of the natural values of the factors will be performed according to the following formula:

$x_{i}=\frac{\tilde{x}_{i}-x_{i 0}}{J_{i}}$ 
where

$x_{i}$ is the natural value of the factor,

$\tilde{x}_{i 0}$ is the main level of the factor,

$J_{i}$ is the interval of variation of the factor.

As a result of coding, all the top levels of the selected factors will take the value +1 , the lower levels -1 , and the main level of the factors will be zero.

In the numerical experiment, a two-level orthogonal plan $2^{4}$ was used, i.e., a full factorial experiment was conducted. The coefficients of the regression equation were determined from the range of application of the factors of the experiment [27]:

$$
B=\left(A^{T} \cdot A\right)^{-1} A^{T} \cdot Y
$$

$\mathrm{A}$ is shown in equation (5); $\mathrm{B}$ is shown in equation (6); $\mathrm{Y}$ is shown in equation (7).

Regression equation has the following form:

$$
\begin{gathered}
Y=b_{0}+b_{1} X_{1}+b_{2} X_{2}+b_{3} X_{3}+b_{5} X_{1} X_{2}+b_{6} X_{1} X_{3}+b_{7} X_{1} X_{4}+ \\
b_{8} X_{2} X_{3}+b_{9} X_{2} X_{4}+b_{10} X_{3} X_{4}+b_{11} X_{1} X_{2} X_{3}+b_{12} X_{1} X_{2} X_{4}+ \\
b_{13} X_{1} X_{3} X_{4}+b_{14} X_{2} X_{3} X_{4}+b_{15} X_{1} X_{2} X_{3} X_{4} \\
\text { In equation (4): } X_{\text {max }}^{X_{\text {max }}}=1 m ; X_{1}^{m_{\text {min }}}=0.9 m ; X_{2}=0.025 m ; X_{2}^{\text {min }}=0.015 m ;
\end{gathered}
$$

$$
X_{3}^{\square}=80 \mathrm{deg} ; X_{3}{ }_{3}^{\min }=70 \mathrm{deg} ; X_{4}{ }^{\max }=\frac{5}{6} \mathrm{deg} ; X_{4}{ }^{\min }=\frac{1}{2} \mathrm{deg}
$$

where the values of bi are determined by the vector column B of the equation (8). In the equation (9), $\mathrm{Y}$ is the function of the circular slip path $\Delta \mathrm{l} \rho$.

The matrix of the numerical experiment was determined by encoding the main factors (2) and their interactions of the second, third, and fourth order (equation (4)) and has the following form: 


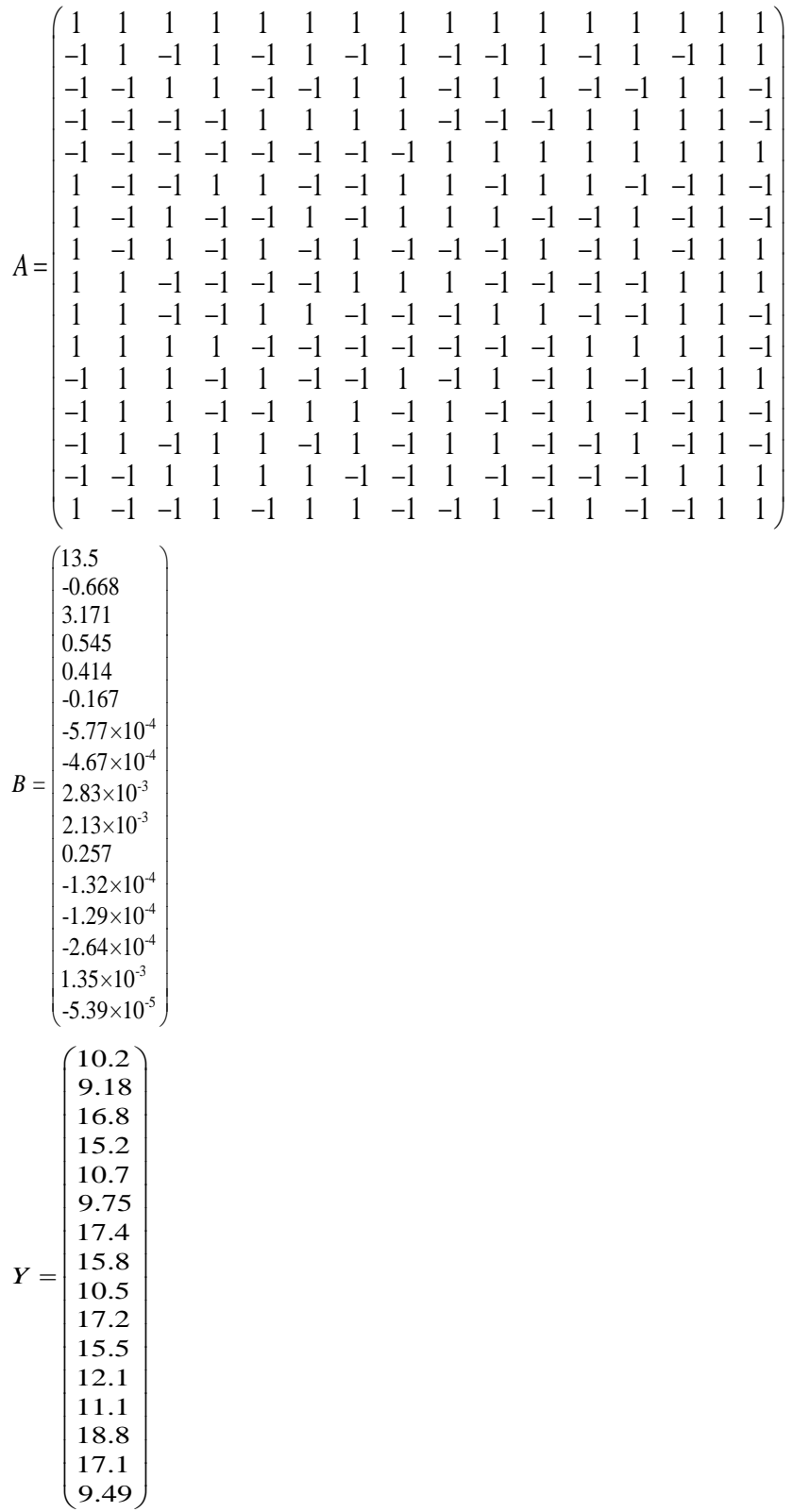

(6)

(7)

And searching for the minimum slip path, the Box-Wilson method or the steep ascent method was applied. Moving along the gradient from the center of the experiment, the minimum value of the slip path was obtained, equal to $\Delta \mathrm{l} \rho,=6.07$ $\mathrm{m}$, which is $30 \%$ less than the previously obtained values when moving from other centers of the numerical experiment. This determines the completion of the numerical optimization of the circular slip path. 
Numerical optimization of the geometrical parameters of the circular slip path (1) when using the tools of the theory of experiment planning is a preliminary stage, which makes it possible to reduce the subsequent costly field experiment significantly. The choice of the theory of experiment planning as an optimization tool [36] is explained by the fact that it is widely used by scientists and production workers in the study of various processes and devices. The change in the optimization tools in the numerical simulation and the subsequent field experiment is, in the authors' opinion, inexpedient. The resulting reduction in the circular slip path by optimizing the geometric parameters of the wheel/rail interface leads to lower consumption of lubricants.

\section{Finite Element Models}

The use of lubrication in curves also affects the stress-strain state of the "wheelrail" system. Friction forces in the lateral contact zone of the wheel flange and the railhead change the configuration of interaction, adding significant longitudinal forces to the contact zone, the maximum value of which is limited by the friction force in the contact zone until the moment of slipping. A quantitative assessment of the above phenomenon was carried out in the environment of finite element modeling - a modern method that is widely used to solve a wide range of problems, including problems of mechanics of deformable solids and others [37, 38]. For this, three-dimensional model of the interaction of a new wheel and a new rail with full geometric similarity to full-scale structures has been developed GOST 10791-2011 and GOST R 51685-2013.

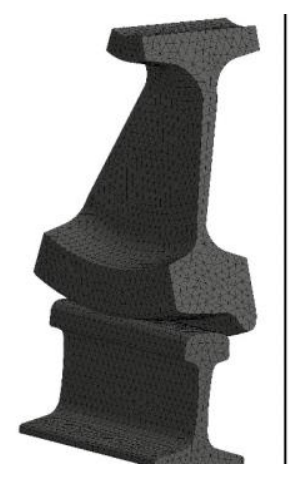

Finite element model of the "wheel-rail" system

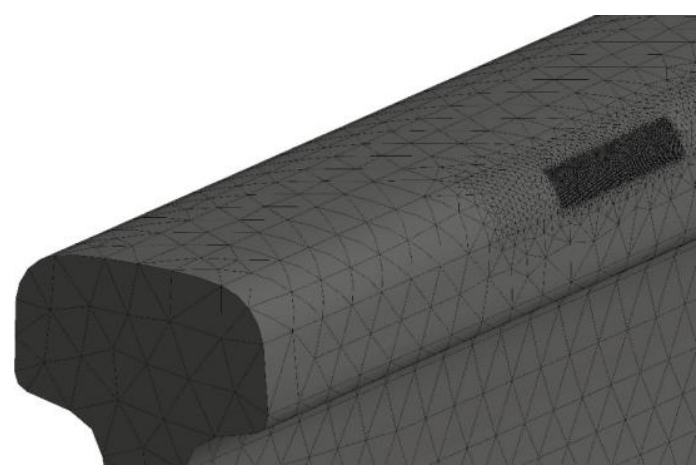

Figure 4

The capacity of finite element models is about 850 thousand knots. In the contact area, the element size is significantly reduced $(0.3-0.4 \mathrm{~mm})$ for the most accurate display of the calculation results. 
The wheel acts on the rail with a lateral force of 10 tons - these are the values of lateral forces that have been experimentally recorded in small-radius curves and are confirmed by the results of modeling the dynamics of the interaction between the track and rolling stock. Thus, the maximum torque before the start of the slip process will be:

$$
M_{\text {max }}=F_{f r} \cdot l
$$

where 1 - the shoulder of the moment of forces and the distance from the axis of rotation of the wheel to the point of the flange contact.

The maximum value of the frictional forces depends on the side load and the coefficient of friction (adhesion) $\mu$ :

$$
F_{f r}=F_{a x} \cdot \mu F_{f r}=F_{a x} \cdot \mu
$$

When assessing the stress-strain state of the lateral contact, the value of 1 is determined as the distance from the axis of rotation of the wheel to the point of the flange contact.

When solving, the following boundary conditions and loads were used:

- Anchoring is modeled along the rail foot area,

- The contact surface of the wheel and axle moves with two-point contact in the vertical and horizontal direction,

- Other elements are not fixed,

- The force is applied using a "distance point", which makes it possible to simulate the effect of axial load as close as possible to the real physical process that occurs during contact.

Initial data parameters:

- Wagon wheel with a diameter of $950 \mathrm{~mm}$,

- Lateral force 10 tons,

- Values of torques (justify where and under what conditions slip lengths):
$2.91 \mathrm{kN} \mathrm{m}$
$5.82 \mathrm{kN} \mathrm{m}$
$8.73 \mathrm{kN} \mathrm{m}$
$11.64 \mathrm{kNm}$,

- The axle of the wheel is in a vertical position,

- Rail axis with an inclination of $1 / 20$,

- Contact surfaces in accordance with the specified profile.

The contours of equivalent stresses, as well as normal stresses on the side surface of the rail, including when adding torque, are shown in Figures 5 and 6. 


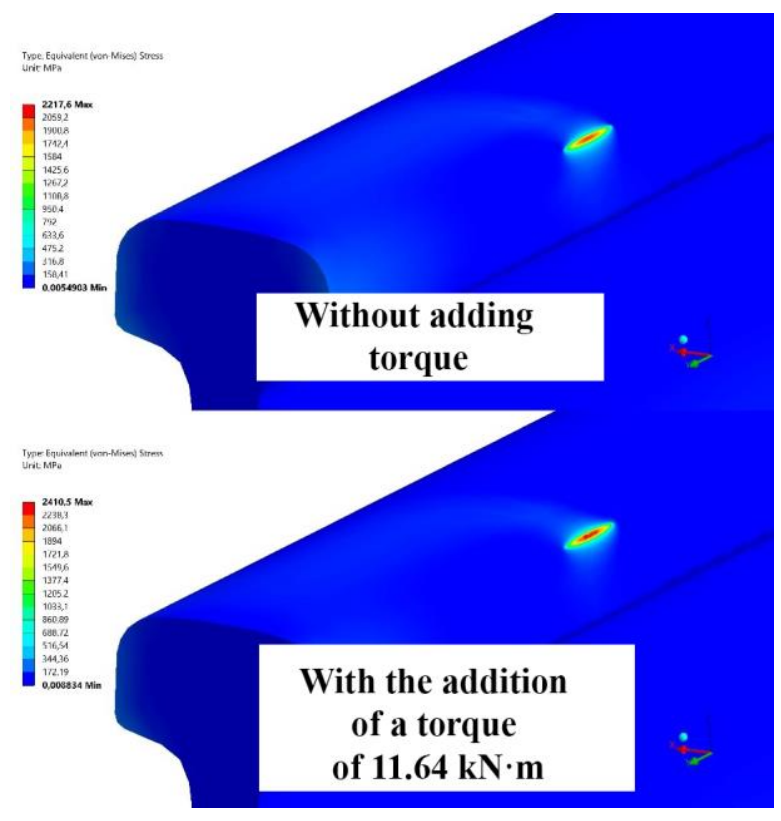

Figure 5

Equivalent stresses on the rail surface

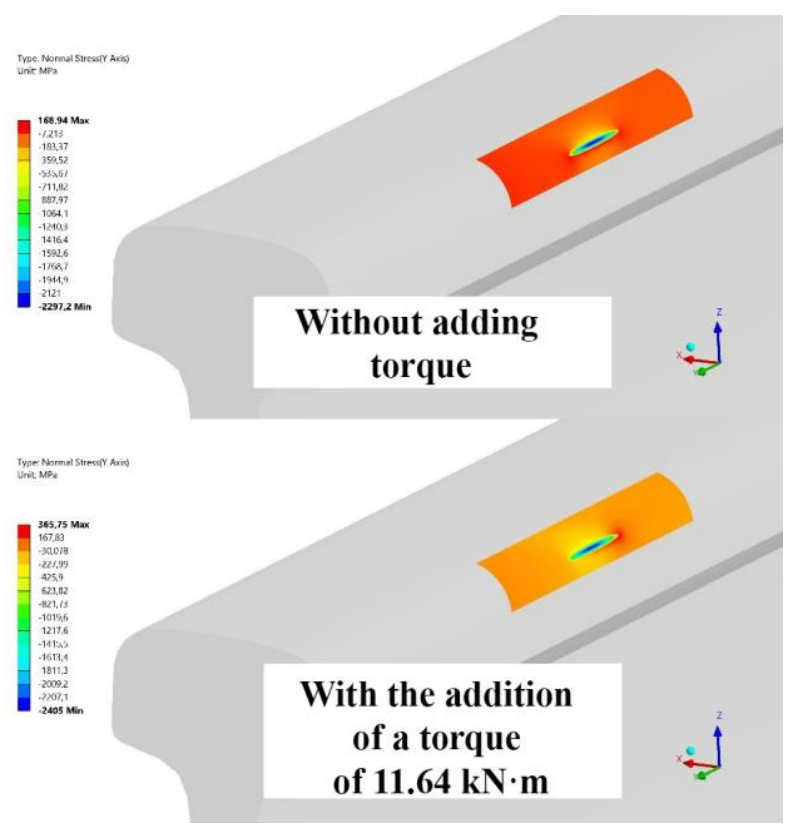

Figure 6

Normal stresses on the rail surface 
The results are summarized in Table 1.

Table 1

Stress-strain state of the "wheel-rail" system in the study of the influence of the friction force in the contact zone

\begin{tabular}{|c|c|c|c|}
\hline \multirow{2}{*}{$\begin{array}{c}\text { Torque value, } \\
\mathrm{Nm}\end{array}$} & \multirow{2}{*}{$\begin{array}{c}\text { Equivalent } \\
\text { stresses, } \mathrm{MPa}\end{array}$} & \multicolumn{2}{|c|}{ Normal stresses, MPa } \\
\cline { 3 - 4 } & 2217.6 & Minimum value & Maximum value \\
\hline 0 & 2225.7 & -2297.2 & 168.94 \\
\hline 2910 & 2247.1 & -2307 & 187.3 \\
\hline 5820 & 2311.1 & -2339.5 & 253.79 \\
\hline 8730 & 2410.5 & -2405 & 312.18 \\
\hline 11640 & & 365.75 \\
\hline
\end{tabular}

The increase in the equivalent stresses is about $9 \%$, while the increase in the maximum normal stresses on the surface is more than $116 \%$, i.e., more than 2 times. From the point of view of the durability of rail steel, the most unfavorable operating conditions are sharp changes in the stress state from tension to compression and vice versa. When the torque is added, which can be characterized as the addition of the friction coefficient to the contact zone, a sharp increase in compressive stresses on the side surface of the rail is observed together with the same lateral force. Thus, the reduction of the friction coefficient with the help of lubrication is currently an urgent task from the standpoint of increasing the durability of rail steel in small-radius curves.

\section{Conclusions}

As a result of the analysis and planning of the numerical experiment, the optimal geometric parameters of the wheel/rail interface were found, allowing to reduce the circular slip path by $30 \%$. However, the obtained theoretical result can only be the basis for real field planning of an experiment, which makes it possible to significantly narrow the area of the most important geometric parameters for optimizing the wheel/rail interface. Reducing the circular slip path will lower the consumption of expensive lubricants.

Mathematical modeling confirmed the relevance and importance of the use of lubricants, in the lateral contact zone of the "wheel-rail" system, as one of the means of extending the rail service life, in small radius curves.

\section{References}

[1] Faccoli, M., Petrogalli, C., Lancini, M., Ghidini, A., Mazzù, A. Rolling. Contact Fatigue and Wear Behavior of High-Performance Railway Wheel Steels Under Various Rolling-Sliding Contact Conditions. Journal of Materials Engineering and Performance. 2017, 26(7), pp. 3271-3284

[2] Olofsson, U., Lyu, Y. Open System Tribology in the Wheel-Rail Contact-A Literature Review. Applied Mechanics Reviews. 2017, 69(6), p. 060802 
[3] Temple, P. D., Harmon, M., Lewis, R., Temple, B., Jones, D. Optimisation of grease application to railway tracks. Proceedings of the Institution of Mechanical Engineers, Part F: Journal of Rail and Rapid Transit. 2018, 232(5), pp. 1514-1527

[4] Kossov, V., Lunin, A., Spirov, A., Ivaškovska, N., Nikolajevs, A. The technology of rail lubrication by the hauling locomotive in train formation. Procedia Computer Science. 2019, 149, pp. 331-335

[5] Suparno, J., Halim, D. A., Junaidi, Effendy, M., Jamari, J. Materials Science. 2019, 961, pp. 126-133

[6] Razak, I. H. A., Ahmad, M. A., Puasa, S. W. Tribological and physiochemical properties of greases for rail lubrication. Tribology Online. 2019, 14(5), pp. 293-300

[7] Viana, T. G., Tressia, G., Sinatora, A. Sliding wear of rail and wheel steels: Effect of hardness ratio, normal load and lubrication. Tribology in Industry 2020, 42(3), pp. 428-442

[8] Vásquez-Chacón, I. A., Gallardo-Hernández, E. A., Moreno-Ríos, M., ViteTorres, M. Influence of surface roughness and contact temperature on the performance of a railway lubricant grease. Materials Letters. 2020, 285, p. 129040

[9] Jover, V., Gaspar, L., Fischer, S. Investigation Of Geometrical Deterioration of Tramway Tracks. Science and Transport Progress. Bulletin of Dnipropetrovsk National University of Railway Transport: 2020, 2(86), pp. $46-59$

[10] A. Nemeth, S. Fischer, Investigation of glued insulated rail joints with special fiber-glass reinforced synthetic fishplates using in continuously welded tracks. Pollack Periodica. 2018, 13(2), pp. 77-86

[11] Shvets, A. O. Dynamic interaction of a freight car body and a three-piece bogie during axle load increase. Vehicle System Dynamics, AHEAD-OFPRINT, 2021, pp. 1-23

[12] He, C., Zhou, S., Di, H., Zhang, X. Effect of longitudinal joint on traininduced vibrations from subway shield-driven tunnels in a homogeneous half-space, International Journal of Transportation Science and Technology, 2021

[13] Shvets, A. O. Analysis of the dynamics of freight cars with lateral displacement of the front bogie. Advanced Mathematical Models and Applications, 2021, 6(1), pp. 45-58

[14] Xu, J., Ma, Q., Wang, X., Wang, P., Wei, X., M. Ahmadian. Investigation on the motion conditions and dynamic interaction of vehicle and turnout due to differential wheelset misalignment, Vehicle System Dynamics, 2021, pp. 1-21 
[15] Dmitry Ovchinnikov, Alexey Bondarenko, Lei Kou, Mykola Sysyn. Extending service life of rails in the case of a rail head defect. Građevinar. 2021, pp. 177-183

[16] Mykola Sysyn, Ulf Gerber, Franziska Kluge, Olga Nabochenko, Vitalii Kovalchuk. Turnout remaining useful life prognosis by meansof on-board inertial measurements on operationaltrains. International Journal of Rail Transportation. 2019, $8(1), \quad$ pp. $1-23, \quad$ DOI: $10.1080 / 23248378.2019 .1685918$

[17] Dmytro Kurhan. Determination of Dynamic Loads From the Wheel on the Rail For High-Speed Trains. Science and Transport Progress Bulletin of Dnipropetrovsk National University of Railway Transport. 2015, 3(57)

[18] Kurhan, D., Kurhan, M., Husak, M. Impact of the variable stiffness section on the conditions of track and rolling stock interaction IOP Conference Series: Materials Science and Engineering. 2014, 985(1), p. 012005

[19] Yuan Gao , Jingmang Xu , Yibin Liu, Zhiguo Dong, Ping Wang, Ziqing Jiang. An investigation into transient frictional rolling contact behaviour in a switch panel: validation and numerical simulation. Vehicle System Dynamics, 2014, DOI: 10.1080/00423114.2020.1802492

[20] Mykola Sysyn, Franziska Kluge, Dmitri Gruen, Vitalii Kovalchuk, Olga Nabochenko. Experimental Analysis of Rail Contact Fatigue Damage on FrogRail of Fixed Common Crossing 1:12. Journal of Failure Analysis and Prevention. 2019, 19(21)

[21] Vitalii Kovalchuk, Mykola Sysyn, Ulf Gerber, Olga Nabochenko, Jandab Zarour, Dehne Stefan. Experimental investigation of the influence of train velocity and travel direction on the dynamic behavior of stiff common crossings. Facta University, Series: Mechanical Engineering. 2019, 17(3), pp. 345-356

[22] Banić M., Miltenović A., Pavlović M., Ćirić I. Intelligent machine vision based railway infrastructure inspection and monitoring using UAV. Facta University, Series: Mechanical Engineering. 2019, 17(3), pp. 357-364

[23] Yang G., Zhao F., Li Q., Liang Y., Lin G. Study of Influences of Highspeed Train Wheel-rail Contact Geometric Parameters on Wheel-rail Wear. Journal of the China Railway Society, 2019, 41(2), pp. 50-56

[24] Chang C., Wang C. Wheel-rail steady state rolling contact analysis based on ale finite element method. China Railway Science. 2009, 30(2), pp. 8793

[25] Kampczyk, A., Dybel, K. The fundamental approach of the digital twin application in railway turnouts with innovative monitoring of weather conditions. Sensors. 2021, 21(17), p. 5757

[26] J. N. Costa, P. Antunes, H. Magalhães, J. Pombo, J. Ambrósio. A finite element methodology to model flexible tracks with arbitrary geometry for railway dynamics applications. Computers and Structures. 2021, 254(1) 
[27] Milošević M., Miltenović A., Banić M., Tomić M. Determination of residual stress in the rail wheel during quenching process by FEM simulation. Facta University, Series: Mechanical Engineering. 2017, 15(3), pp. 413-425

[28] Verigo M. F. Vzaimodeystvie puti i podvizhnogo sostava v krivykh malogo radiusa $\mathrm{i}$ borba s bokovym iznosom relsov i grebney koles [Interaction of the track and rolling stock on the curves of small radius and the fight against lateral wear of rails and wheel flanges] Moscow, PTKB TSP MPS, 1997

[29] Lysiuk V. S., Bugaenko V. M. Povrezhdeniya relsov i ikh diagnostika [Rail damage and diagnostics] Moscow, IKTS Akademkniga, 2006, p. 638

[30] Lysiuk V. S. Prichiny i mekhanizm bokovogo iznosa relsov i grebny koles [Causes and mechanism of lateral wear of rails and wheel flanges] Put $i$ putevoe khozyaystvo, 1997, pp. 13-19

[31] The concept of development of the technology of lubrication of the contact zone "wheel-rail" in JSC "Russian Railways": approved by order of JSC RZD dated January 16, 2015, 60(5)

[32] E. V. Eliseev, O. A. Pashenceva, A. I. Gosman, D. B. Konovalov. Sistemy smazki: effektivnoe umen'shenie iznosa [Lubrication systems: effective reduction of wear] Put' i putevoe hozyajstvo, 2012, 1, pp. 5-9

[33] Harris U. J., Zakharov S. M., Landgren J., Turne Kh., Eberson V. Obobshchenie peredovogo opyta tyazhelovesnogo dvizheniya: voprosy vzaimodeystviya kolesa i rel'sa [Generalization of advanced experience on heavy-weight movement: issues of wheel and rail interaction, EnglishRussian translation] Moscow, Intext, 2002, p. 408

[34] Broek D. M. Osnovy mekhaniki razrusheniya [Elementary engineering fracture mechanics, English-Russian translation] Moscow, Vysshaya shkola, 1980, p. 368

[35] Krachsavskiy I. B., Dobychin N. M., Kombalov V. S. Osnovy raschetov na trenie i iznos [Basics of calculations for friction and wear] Moscow, Mashinostroenie, 1997, p. 526

[36] Adler A. S., Markova R. N., Granovskiy V. N. Planirovanie optimalnogo eksperimenta [Planning an optimal experiment] Moscow, Nauka, 1976

[37] D. V. Ovchinnikov, V. A. Pokatskiy. Assessment of the stability of a continuous welded track using the finite element method. Modern issues in railway track design, construction and operation, 2012, pp. 206-210

[38] Dmitry Ovchinnikov, Vladimir Pokatsky, Damir Gallyamov. Factors Affecting the Dynamic Rail Canting of the Railway Track Transportation Research Procedia, 2021, 54, pp. 544-551 